\title{
Differences in Muscle Metabolism in Patients With Type I Diabetes - Influence of Gender and Nephropathy Studied by ${ }^{31}$ P MR Spectroscopy
}

\author{
P. SEDIVY ${ }^{1,2}$, M. DEZORTOVA ${ }^{1}$, M. DROBNY ${ }^{1}$, Z. VLASAKOVA ${ }^{3}$, V. HERYNEK ${ }^{1}$, \\ M. HAJEK ${ }^{1}$
}

${ }^{1}$ MR-Unit, Department of Diagnostic and Interventional Radiology, Institute for Clinical and Experimental Medicine, Prague, Czech Republic, ${ }^{2}$ First Medical Faculty of Charles University, Prague, Czech Republic, ${ }^{3}$ Center of Diabetology, Institute for Clinical and Experimental Medicine, Prague, Czech Republic

Received August 15, 2017

Accepted December 11, 2017

On-line March 12, 2018

\section{Summary}

Type I diabetes mellitus (DM1) is a complex disease with adverse effects on organs and tissues despite compensation by insulin treatment. The goal of our study was to study how kidney diseases change ${ }^{31} \mathrm{P} M R$ parameters of muscle metabolism in DM1 patients with respect to gender. $51 \mathrm{DM} 1$ patients $(19 \mathrm{~m} / 14 \mathrm{f}$ without and $13 \mathrm{~m} / 5 \mathrm{f}$ with nephropathy) and 26 (14 m/12 f) healthy volunteers were examined using ${ }^{31} \mathrm{P}$ magnetic resonance spectroscopy at 3T tomograph at rest, and during and after a calf muscle exercise. The exercise consisted of a six-minute plantar flexion using a pedal ergometer followed by a six-minute recovery. It is reflected by reduced relative $\beta$-ATP and increased $\mathrm{Pi}$ and phosphodiester signals to phosphocreatine $(\mathrm{PCr})$ at rest and prolongation of the $\mathrm{PCr}$ recovery time after the exercise. Measurement on healthy volunteers indicated differences between males and females in $\mathrm{pH}$ at the rest and after the exercise only. These differences between patients groups were not significant. We have proven that nephropathy affects the metabolism in diabetic patients and our results confirm significant difference between patients with and without nephropathy. Gender differences in $\mathrm{pH}$ were observed only between male and female healthy volunteers.

\section{Key words}

Magnetic resonance spectroscopy • Diabetes Mellitus Type I • Energy metabolism

\section{Corresponding author}

M. Hájek, MR-Unit, Department of Diagnostic and Interventional Radiology, Institute for Clinical and Experimental Medicine, Videnska 1958/9, 14021 Prague 4, Czech Republic. E-mail: miha@medicon.cz

\section{Introduction}

Phosphorous magnetic resonance spectroscopy $\left({ }^{31} \mathrm{P}\right.$ MRS) is a noninvasive method allowing for in vivo investigation of energy metabolism in muscles based on detecting ${ }^{31} \mathrm{P}$ signals originated from phosphocreatine $(\mathrm{PCr})$, inorganic phosphate $(\mathrm{Pi})$, adenosine triphosphate (ATP), phosphodiesters (PDE), phosphomonoesters (PME) and nicotinamide adenine dinucleotide (NADH) (Valkovič et al. 2017, Argov et al. 2000). In addition, intramyocellular (IMCL) $\mathrm{pH}$ can be determined from chemical shift differences between PCr and Pi (Moon and Richards 1973). During dynamic ${ }^{31} \mathrm{P}$ MRS, physical exercise and measurement of ${ }^{31} \mathrm{P} \mathrm{MR}$ spectra from muscle are combined (Sedivy et al. 2015, Kemp et al. 2015, Kemp and Radda 1994).

During a physical exercise, the muscle uses energy from ATP, which is immediately resynthesized from $\mathrm{PCr}$ through creatine-kinase reaction. $\mathrm{PCr}$ drop is stopped by two mechanisms that produce ATP during exercise. The first mechanism is anaerobic glycolysis that provides ATP during the exercise activity. It generates 
protons and causes a decrease in muscle $\mathrm{pH}$ (Kemp et al. 2001, Robergs et al. 2004). The second process is oxidative phosphorylation, which continues after the exercise. During exercise and recovery period changes of $\mathrm{PCr}, \mathrm{Pi}$ and $\mathrm{pH}$ are monitored and other important parameters as mitochondrial capacity could be calculated $\left(\mathrm{Q}_{\max }\right)$ (Kemp and Radda 1994). Mitochondrial capacity expresses the maximal possible extent of mitochondrial aerobic metabolism. A high mitochondrial capacity calculated from ${ }^{31} \mathrm{P}$ MRS is associated with a good function of mitochondria and correlates well with oxidative capacity of mitochondria isolated from muscle biopsies (Lanza et al. 2011).

Patients with type I diabetes mellitus (DM1) suffer from the lack of insulin due to the autoimmune destruction of the insulin-producing beta cells in the pancreas. Insulin regulates the uptake of glucose into muscle cells via the GLUT-4 transporter. Insulin also promotes glycogen, lipid and protein synthesis in muscle cells, while suppressing lipolysis and gluconeogenesis from muscle amino acids; therefore, it is closely related to energy metabolism (Wilcox 2005).

Even in the case of insulin substitution therapy, glycemia in DM1 patients often oscillates between hyperand hypoglycemic levels. Poorly managed DM1 may lead eventually to cardiovascular diseases, diabetic neuropathy, retinopathy, nephropathy or a diabetic foot syndrome (Brownlee 2001). A number of DM1 patients also exhibit insulin resistance (Bergman et al. 2012, Cree-Green et al. 2015) and higher deposition of IMCL fat (Perseghin et al. 2003) similarly as in DM2 patients owing to impaired mitochondrial metabolism (Szendroedi et al. 2008, Petersen et al. 2004).

Changes in mitochondrial metabolism in DM1 were proven by in vitro studies, which revealed changes in mitochondrial gene expression (Antonetti et al. 1995, Karakelides et al. 2007) with a reduction in ATP production. The change of mitochondrial function in diabetes mellitus is explained by glucose toxicity (Rossetti et al. 1995, Rabol et al. 2009), lipotoxicity (Perseghin et al. 2003), the effect of chronic hyperinsulinemia (Karakelides et al. 2007) or by reduced nutrient delivery due to limited insulin action and glucose transport (Yki-Jarvinen et al. 1990) or as a result of a reduced muscle blood flow and oxygen supply attributable to microangiopathy (Cree-Green et al. 2015).

Only a few dynamic in vivo studies were performed on type I diabetes mellitus (Cree-Green et al. 2015, Crowther et al. 2003, Item et al. 2011).
A significantly decreased mitochondrial capacity was found in DM1 patients (males only) compared to controls (Crowther et al. 2003). Mean mitochondrial capacity in female patients did not change in comparison with female controls (Item et al. 2011) but a negative correlation between the value of glycosylated hemoglobin and the individual mitochondrial capacity was noted. Although specific differences were described separately for males and females (Crowther et al. 2003, Item et al. 2011), these studies did not compare males and females directly and provided somewhat contradictory results.

One of the most serious complications of diabetes mellitus is nephropathy. It is characterized as insufficient kidney function; it means that concentrations of several ions, creatine, urea, etc. are increasing in blood. In addition, metabolism of amino acids is negatively affected and patients suffer from the erythropoietin and vitamin D deficiency. In this condition the skeletal muscles are atrophied (Fahal 2014) and energy metabolism is impaired (Táborský et al. 1993, Kemp et al. 1995). Nephropathy patients have bigger drop of $\mathrm{PCr}$ and $\mathrm{pH}$ during exercise (Kemp et al. 1995) and lower PCr/Pi ratio at rest (Táborský et al. 1993).

The aim of our study was to answer the following two questions:

1) Can we see gender specific differences in the rest and dynamic ${ }^{31} \mathrm{P}$ parameters in our DM1 patients and controls?

2) How nephropathy in DM1 patients changes the rest and dynamic ${ }^{31} \mathrm{P}$ parameters?

\section{Methods}

\section{Subjects}

Overall 51 diabetic patients $(32 \mathrm{~m} / 19 \mathrm{f})$ were recruited for the study from our Department of diabetology according to their clinical examinations and laboratory results. In addition 12 healthy females $(\mathrm{Cf})$ and 14 healthy males $(\mathrm{Cm})$ participated in the study as control groups. Based on questionnaire none of them was an active sportsman and all had predominantly sedentary jobs.

The subjects were divided into subgroups according the gender (male $-\mathrm{m}$; female $-\mathrm{f}$ ) and clinical diagnosis (controls $-\mathrm{C}$; patients without nephropathy DM1; patients with nephropathy - DM1N) (Table 1). Subjects with a low workload during the exercise (drop of Cr lower than $15 \%)$ were excluded $(6 \mathrm{~m} / 2 \mathrm{f}$ patients) from the study. Diabetic patients were treated by insulin 
substitution therapy; patients with nephropathy suffered from kidney failure and were on a waiting list for kidney transplantation. The age, BMI, glycosylated hemoglobin
(HbAlc) and creatinine from blood samples (results from clinical reports) of all subgroups are listed in Table 1.

Table 1. Age, body mass index (BMI), disease length, and selected biochemical data (glycosylated hemoglobin - HbA1c, and creatinine evaluated from blood tests) of the evaluated groups of patients and controls. Mean values \pm standard deviations are listed.

\begin{tabular}{|c|c|c|c|c|c|}
\hline Subject group & Age (years) & $\begin{array}{c}\text { BMI } \\
\left(\mathbf{k g} / \mathbf{m}^{2}\right)\end{array}$ & $\begin{array}{l}\text { Length of the } \\
\text { disease (years) }\end{array}$ & HbA1c (\%) & $\begin{array}{l}\text { Creatinine } \\
(\mu \mathrm{mol} / \mathrm{l})\end{array}$ \\
\hline Cm (14) & $32 \pm 9$ & $26 \pm 4$ & 0 & {$[3.1 \pm 0.17]$} & $84 \pm 8$ \\
\hline DM1m (19) & $35 \pm 11$ & $24 \pm 4$ & $12 \pm 8$ & $7.2 \pm 1.8$ & $81 \pm 13$ \\
\hline$D M 1 m N$ (13) & $44 \pm 9$ & $27 \pm 4$ & $28 \pm 6$ & $7.1 \pm 1.5$ & لـ \\
\hline$C f(12)$ & $40 \pm 10$ & $25 \pm 4$ & 0 & {$[3.7 \pm 0.37$} & $70 \pm 7$ \\
\hline$D M 1 f(14)$ & $38 \pm 13$ & $27 \pm 4$ & $17 \pm 13$ & $7.5 \pm 1.5^{ل}$ & $64 \pm 11$ \\
\hline$D M 1 f N(5)$ & $33 \pm 7$ & $24 \pm 4$ & $22 \pm 5$ & $7.4 \pm 1.9$ J & لـ \\
\hline$C(26)$ & $36 \pm 10$ & $25 \pm 4$ & 0 & $3.4 \pm 0.47$ & $77 \pm 11$ \\
\hline DM1 (33) & $36 \pm 12$ & $25 \pm 4$ & $18 \pm 10$ & $7.3 \pm 1.7$ & $74 \pm 15$ \\
\hline$D M 1 N(18)$ & $41 \pm 9$ & $26 \pm 4$ & $26 \pm 6$ & $7.2 \pm 1.6$ & لـ \\
\hline
\end{tabular}

Cm - control males, Cf - control females, C - control males and females, DM1m - diabetic males, DM1f - diabetic females, DM1 - diabetic males and females, DM1mN - diabetic males with nephropathy, DM1fN - diabetic females with nephropathy, DM1N - diabetic males and females with nephropathy; significant differences $(p<0.05)$ are labeled.

In addition, ten healthy volunteers were examined to assess the quality measurement of the ${ }^{31} \mathrm{P}$ MR spectroscopy of the calf muscle at rest: five of them were examined three times in independent sessions and five volunteers once with three measurements. Long-term reproducibility of the dynamic protocol for the assessment of mitochondrial capacity was tested on two healthy subjects ( 25 and 65 years old): 3 and 5 dynamic ${ }^{31} \mathrm{P}$ MRS examinations were performed in three and five subsequent weeks in the same time of the day.

All subjects were informed about the examination protocol and they signed their consent with the study. The study was approved by the local ethics committee. All subjects also filled out a questionnaire about their physical condition, sport activities and living habits.

\section{MR examination}

MR examinations were performed using a whole-body 3T MR system TRIO (Siemens, Erlangen, Germany) with a dual-channel ${ }^{1} \mathrm{H} /{ }^{31} \mathrm{P}$ surface coil (Rapid Biomedical, Rimpar, Germany). All subjects were examined in a supine position with the coil fixed under the musculus gastrocnemius. The positioning of the muscle over the coil was verified using a localizer sequence. ${ }^{31} \mathrm{P}$ MR spectra at rest were acquired by a nonlocalized acquisition sequence FID with the following parameters: acquisition delay $\mathrm{TE}^{*}=0.4 \mathrm{~ms}, \mathrm{TR}=15 \mathrm{~s}$, number of acquisitions NA=16, vector size of 1024 . Magnetic field homogeneity was optimized by the localized shimming of the water signal.

Dynamic ${ }^{31} \mathrm{P}$ MR spectra were obtained by the FID sequence with the following parameters: $\mathrm{TE}^{*}=0.4 \mathrm{~ms}, \mathrm{TR}=2 \mathrm{~s}, \mathrm{NA}=1$, vector size of 1024 ; number of measurements $=420$. Our standard exercise examination protocol was divided into three parts: a two-minute rest period, a six-minute exercise period and a six-minute recovery period. The exercise was performed with a home-built ergometer by the plantar flexion twice per repetition time ( $2 \mathrm{~s}$ ) with a power below $60 \%$ of maximal power that had been measured by dynamometer, for more details see (Sedivy et al. 2015). Acoustic synchronization was used to navigate the subjects during the exercise period of the experiment.

\section{Spectra evaluation}

Spectra were analyzed by the AMARES time domain fitting routine (drawing upon prior knowledge) (Vanhamme et al. 1997) in the jMRUI 5.0 software package. Lorentzian line shapes were used for the fitting 
of singlets of PCr, Pi, PDE (glycerol-3-phosphorylcholine and glycerol-3-phosphorylethanolamine), PME (phosphorylcholine and phosphorylethanolamine) and NADH signals. The ATP peaks were fitted as two doublets $(\alpha$-ATP, and $\gamma$-ATP) and a triplet ( $\beta$-ATP). Integral intensities were related to total integral of the whole spectra $\left(\mathrm{P}_{\text {tot }}\right)$.

The relative chemical shift of $\mathrm{Pi}$ and $\operatorname{PCr}(\delta$ in ppm) was used to calculate the intracellular $\mathrm{pH}$ according to the Henderson-Hasselbalch equation (Moon and Richards 1973):

$$
\mathrm{pH}=6.75+\log \left[\left(\delta \mathrm{P}_{\mathrm{i}}-3.27\right) /\left(5.63-\delta \mathrm{P}_{\mathrm{i}}\right)\right]
$$

The $\mathrm{PCr}$ changes during the recovery period were fitted by a mono-exponential function to evaluate the $\mathrm{PCr}$ recovery rate:

$$
[\mathrm{PCr}](t)=[\mathrm{PCr}]_{\mathrm{e}_{-} \mathrm{ex}}+\Delta[\mathrm{PCr}]\left(1-\mathrm{e}^{-\mathrm{t} / \tau} \mathrm{PCr}\right)
$$

where $t$ is time, $[\mathrm{PCr}]_{e_{-} \text {ex }}$ is the $\mathrm{PCr}$ amount at the end of the exercise, $\Delta[\mathrm{PCr}]$ is the difference in the $\mathrm{PCr}$ amount at rest and at the end of the exercise, and $\tau_{\mathrm{PCr}}$ is the time constant of the $\mathrm{PCr}$ recovery rate.

The initial $\mathrm{PCr}$ recovery rate $\left(\mathrm{V}_{\mathrm{iPCr}}\right)$ roughly representing the ATP turnover at the end of the exercise was calculated as follows:

$$
\mathrm{V}_{\mathrm{iPCr}}=[\mathrm{PCr}] / \tau_{\mathrm{PCr}}
$$

Mitochondrial capacity $\mathrm{Q}_{\max }$ was calculated according to the model of Michaelis-Menten, taking into account adenosine diphosphate at the end of the exercise activity $[\mathrm{ADP}]_{\mathrm{e} \_\mathrm{ex}}, \mathrm{V}_{\mathrm{iPCr}}$, and the Michaelis-Menten constant $\left(\mathrm{K}_{\mathrm{m}}\right)$, which was assumed to be $30 \mu \mathrm{M}$ (Kemp 1994):

$$
\mathrm{Q}_{\max }=\mathrm{V}_{\mathrm{iPCr}}\left(1+\mathrm{K}_{\mathrm{m}} /[\mathrm{ADP}]_{\mathrm{e}_{-} \mathrm{ex}}\right)
$$

where $[\mathrm{ADP}]_{\mathrm{e} \text { ex }}$ was calculated according to the method described by Kemp et al. (1993), assuming constant total creatine concentration throughout all measurements and $15 \%$ of total creatine not being phosphorylated in the resting state (Boska 1994)

$$
[\mathrm{ADP}]_{\mathrm{e} \_\mathrm{ex}}=[\mathrm{Cr}][\mathrm{ATP}] /[\mathrm{PCr}]\left[\mathrm{H}^{+}\right] \mathrm{K}_{\mathrm{CK}}
$$

where $\left[\mathrm{H}^{+}\right]$is the concentration of proton ions and $\mathrm{K}_{\mathrm{CK}}$ is the equilibrium constant.
Absolute concentrations of $\mathrm{PCr}$ necessary for evaluation were calculated from $\mathrm{PCr} / \beta$-ATP ratios assuming constant ATP concentration of $8.2 \mathrm{mM}$ in the muscle tissue (Kemp et al. 2007, Taylor et al. 1986).

\section{Statistical evaluation}

For the comparison of individual parameters of the patient and control groups, statistics was done using the Prism 6 software. According to the Shapiro-Wilk normality tests, parametric or non-parametric multiple comparison (ANOVA Sidak's multiple comparisons and/or Kruskal-Wallis) was undertaken (the probability level of $\mathrm{p}<0.05$ was considered as statistically significant). As some data did not follow normal distribution, Spearman's correlation analysis was conducted (the probability level of $\mathrm{p}<0.005$ was considered as statistically significant).

\section{Results}

An initial test on healthy volunteers revealed that the reproducibility of metabolic ratios measurements at rest are: $\beta-\mathrm{ATP} / \mathrm{P}_{\text {tot }}-3 \%, \mathrm{Pi} / \mathrm{P}_{\text {tot }}-6 \%, \mathrm{PDE} / \mathrm{P}_{\text {tot }}-8 \%$, $\mathrm{PCr} / \mathrm{Pi}-8 \%, \mathrm{pH}-0.2 \%$. The reproducibility of $\mathrm{Q}_{\max }$ and $\tau_{\mathrm{PCr}}$ was found $10 \%$, and $25 \%$, resp.

Groups of patients and controls did not significantly differ in terms of the mean age and BMI independently of gender (Table 1). As expected, the creatinine was significantly higher in patient groups with nephropathy from the others. Similarly, significantly higher values of HbA1c were found in DM1 and DM1N groups compared to healthy controls.

The results of ${ }^{31} \mathrm{P}$ MR spectroscopy at rest and exercise are summarized in Tables 2 and 3 . Signal intensities of PCr, Pi, $\beta$-ATP, and PDE related to the total spectrum integral $\left(\mathrm{P}_{\text {tot }}\right)$ and $\mathrm{pH}$ were evaluated at rest. Significantly decreased $\beta-\mathrm{ATP} / \mathrm{P}_{\text {tot }}$ and increased $\mathrm{Pi} / \mathrm{P}_{\text {tot }}$ and $\mathrm{PDE} / \mathrm{P}_{\text {tot }}$ ratios were observed in nephropatic $\mathrm{DM} 1$ patients to controls; $\beta-\mathrm{ATP} / \mathrm{P}_{\text {tot }}$ was also able to distinguish groups of patients with and without nephropathy. When dividing groups according to gender, only the $\beta-\mathrm{ATP} / \mathrm{P}_{\text {tot }}$ ratio was significantly different between male groups of nephropatic patients and controls. In addition, we found significantly higher $\mathrm{pH}$ in male control group compared to female healthy controls. These gender effects were not observed in patients groups.

The six-minute exercise was sufficient to create equilibrium between the consumption and creation of 
$\mathrm{PCr}$ in most of the subjects, and the six-minute recovery period was also sufficient to fully restore the $\mathrm{PCr}$ signal intensity to the original values in both controls and patients (Fig. 1). We found prolongation of $\tau_{\mathrm{PCr}}$ in patients in the order of $\mathrm{C}<\mathrm{DM} 1<\mathrm{DM} 1 \mathrm{~N}$. However, statistical significance was seen only between the control and nephropathy groups. In addition, a significantly lower
$\mathrm{pH}$ was found in DM1 patients compared to controls. When dividing groups according to gender only trends in dynamic parameters were observed due to a high variance in groups of patients. Measurement on healthy volunteers revealed differences between males and females only in $\mathrm{pH}$ after the exercise, similarly as at rest. The differences in $\mathrm{pH}$ between $\mathrm{Cm}$ and DM1m were observed (Table 3 ).

Table 2. Metabolic concentrations of phosphocreatine $(\mathrm{PCr})$, inorganic phosphate $(\mathrm{Pi})$, adenosine triphosphate (signal of the second phosphate, $\beta-A T P)$, and phosphodiesters (PDE) related to total integral of the phosphorous spectra $\left(P_{\text {tot }}\right)$, and $\mathrm{pH}$ measured at rest evaluated for the patients' groups and controls. Mean values \pm standard deviations are listed.

\begin{tabular}{|c|c|c|c|c|c|}
\hline Subject group & $\mathbf{P C r} / \mathbf{P}_{\text {tot }}$ & $\mathbf{P i} / \mathbf{P}_{\text {tot }}$ & $\beta-A T P / \mathbf{P}_{\text {tot }}$ & $\mathbf{P D E} / \mathbf{P}_{\text {tot }}$ & pH \\
\hline $\mathrm{Cm}$ & $0.49 \pm 0.02$ & $0.06 \pm 0.02$ & $0.101 \pm 0.0097$ & $0.050 \pm 0.017$ & $\Gamma^{7.047 \pm 0.032}$ \\
\hline$D M 1 m$ & $0.50 \pm 0.03$ & $0.07 \pm 0.02$ & $0.101 \pm 0.015$ & $0.051 \pm 0.019$ & $7.032 \pm 0.022$ \\
\hline$D M 1 m N$ & $0.50 \pm 0.02$ & $0.08 \pm 0.01$ & ل & $0.069 \pm 0.021$ & $7.032 \pm 0.018$ \\
\hline$C f$ & $0.50 \pm 0.02$ & $0.06 \pm 0.02$ & $0.093 \pm 0.007$ & $0.053 \pm 0.020$ & $L_{7.019 \pm 0.026}$ \\
\hline$D M 1 f$ & $0.49 \pm 0.04$ & $0.08 \pm 0.03$ & $0.089 \pm 0.011$ & $0.056 \pm 0.015$ & $7.019 \pm 0.019$ \\
\hline$D M 1 f N$ & $0.50 \pm 0.03$ & $0.08 \pm 0.01$ & $0.083 \pm 0.004$ & $0.058 \pm 0.023$ & $7.040 \pm 0.020$ \\
\hline$C$ & $0.497 \pm 0.0214$ & $0.063 \pm 0.0167$ & $0.097 \pm 0.009$ & $0.052 \pm 0.0187$ & $7.03 \pm 0.030$ \\
\hline$D M 1$ & $0.494 \pm 0.0334$ & $0.071 \pm 0.022$ & $0.096 \pm 0.0157$ & $0.053 \pm 0.017$ & $7.03 \pm 0.022$ \\
\hline$D M 1 N$ & $0.497 \pm 0.0248$ & $0.078 \pm 0.015$ & תل $0.085 \pm 0.009$ & ل & $7.03 \pm 0.019$ \\
\hline
\end{tabular}

$\mathrm{Cm}$ - control males, Cf - control females, C - control males and females, DM1m - diabetic males, DM1f - diabetic females, DM1 - diabetic males and females, DM1mN - diabetic males with nephropathy, DM1fN - diabetic females with nephropathy, DM1N - diabetic males and females with nephropathy; significant differences $(p<0.05)$ are labeled.

Table 3. Dynamic parameters - recovery time of phosphocreatine after exercise ( $\left.\mathrm{TPCr}_{\mathrm{r}}\right)$, drop of phosphocreatine during exercise ( $\triangle \mathrm{PCr}$ ), speed of $\mathrm{PCr}$ replenishment $\left(\mathrm{V}_{\mathrm{iPCr}}\right)$, mitochondrial capacity $\left(\mathrm{Q}_{\mathrm{max}}\right)$, and $\mathrm{pH}$ after exercise of the patients' groups and controls. Mean values \pm standard deviations are listed.

\begin{tabular}{|c|c|c|c|c|c|}
\hline Subject group & $\tau_{\mathrm{PCr}}(\mathbf{s})$ & $\Delta \operatorname{PCr}(\%)$ & $\mathrm{V}_{\mathrm{iPCr}}(\mathrm{mmol} / \mathrm{s})$ & $\mathrm{Q}_{\max }(\mathrm{mmol} / \mathrm{s})$ & $\begin{array}{l}\text { pH after } \\
\text { exercise }\end{array}$ \\
\hline $\mathrm{Cm}$ & $53 \pm 24$ & $36 \pm 18$ & $0.32 \pm 0.12$ & $0.58 \pm 0.21$ & 77.002 \\
\hline DM1m & $60 \pm 29$ & $42 \pm 18$ & $0.25 \pm 0.09$ & $0.50 \pm 0.17$ & ] $6.876 \pm 0.197$ \\
\hline$D M 1 m N$ & $87 \pm 70$ & $45 \pm 21$ & $0.30 \pm 0.14$ & $0.51 \pm 0.19$ & $6.895 \pm 0.219$ \\
\hline$C f$ & $42 \pm 11$ & $38 \pm 11$ & $0.42 \pm 0.18$ & $0.71 \pm 0.25$ & $6.945 \pm 0.155$ \\
\hline$D M 1 f$ & $61 \pm 23$ & $45 \pm 16$ & $0.36 \pm 0.12$ & $0.63 \pm 0.16$ & $6.826 \pm 0.134$ \\
\hline$D M 1 f N$ & $80 \pm 56$ & $41 \pm 17$ & $0.31 \pm 0.15$ & $0.52 \pm 0.24$ & $6.970 \pm 0.174$ \\
\hline$C$ & $48 \pm 197$ & $36 \pm 14$ & $0.36 \pm 0.16$ & $0.64 \pm 0.23$ & $6.976 \pm 0.1627$ \\
\hline$D M 1$ & $60 \pm 26$ & $43 \pm 17$ & $0.30 \pm 0.11$ & $0.55 \pm 0.17$ & $6.855 \pm 0.173$ \\
\hline$D M 1 N$ & $85 \pm 65]$ & $44 \pm 20$ & $0.30 \pm 0.14$ & $0.51 \pm 0.20$ & $6.916 \pm 0.206$ \\
\hline
\end{tabular}

Cm - control males, Cf - control females, C - control males and females, DM1m - diabetic males, DM1f - diabetic females, DM1 - diabetic males and females, DM1mN - diabetic males with nephropathy, DM1fN - diabetic females with nephropathy, DM1N diabetic males and females with nephropathy; significant differences $(p<0.05)$ are labeled. 


\section{Correlation analysis}

The length of the disease correlated with the patients' age $(\mathrm{r}=0.46 ; \quad \mathrm{p}=0.0001, \quad$ Spearman's $r$ coefficients and corresponding $p$ values). An increasing BMI correlated with the age $(\mathrm{r}=0.338 ; \mathrm{p}=0.003)$ and was coincidental with the length of the disease $(r=0.46$; $\mathrm{p}=0.0006$ ). From rest ${ }^{31} \mathrm{P}$ MRS parameters $\beta-A T P / P_{\text {tot }}$ positively correlated with $\mathrm{PDE} / \mathrm{P}_{\text {tot }}(\mathrm{r}=0.475 ; \mathrm{p}=0.0001)$ and $\beta-A T P / P_{\text {tot }}$ negatively correlated with age $(r=-0.425$; $\mathrm{p}=0.0001$ ). From dynamic ${ }^{31} \mathrm{P}$ MRS parameters $\mathrm{pH}$ after exercise negatively correlated with $\mathrm{HbAlc}(\mathrm{r}=-0.376$; $\mathrm{p}=0.001$ ).

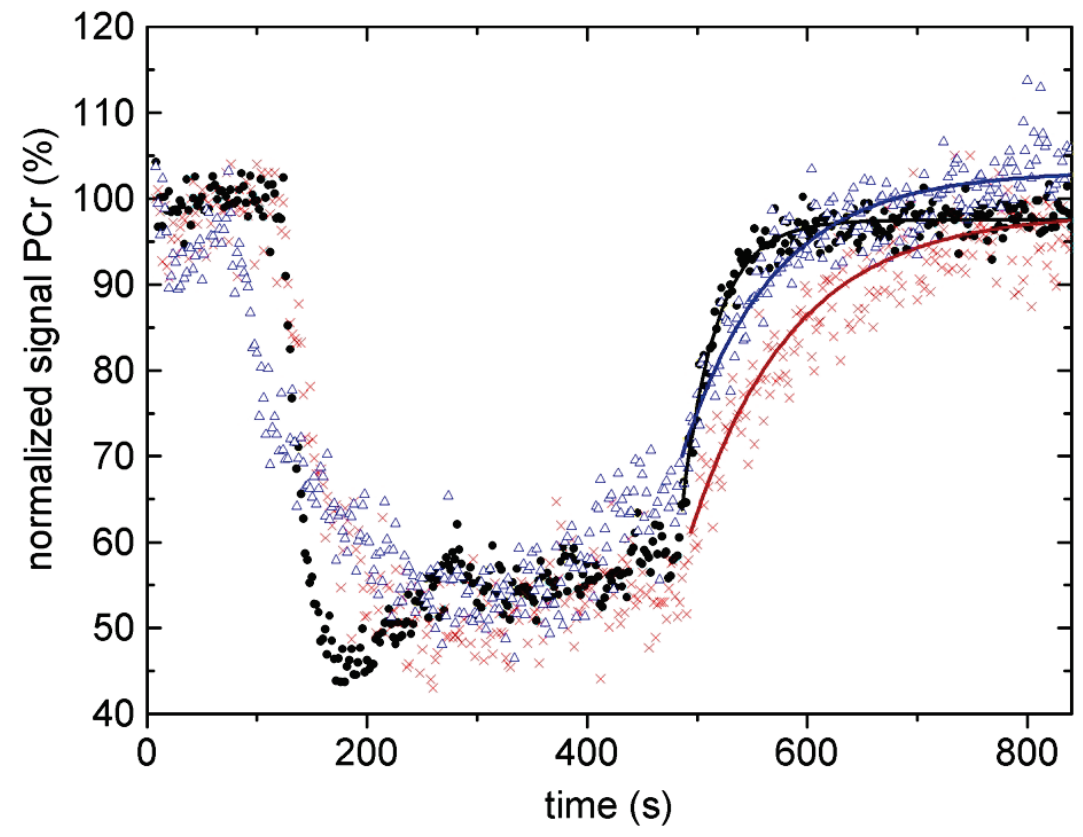

Fig. 1. Typical changes in phosphocreatine (PCr) during the rest exercise - recovery periods during the examination of a female control (black), DM1 patient without (blue) and with (red) nephropathy.

\section{Discussion}

${ }^{31} \mathrm{P}$ MR spectroscopy at rest and under exercise is an interesting tool for investigating energy metabolism in muscles but it has some limitations. A different physical effort of each subject may influence the results. A low drop of the $\mathrm{PCr}$ signal $(\triangle \mathrm{PCr})$ may indicate an insufficient depletion of $\mathrm{PCr}$ and also brings an additional error into the calculation. Therefore, only subjects with $\Delta \mathrm{PCr}>15 \%$ were included in the study. A higher workload helps determine correct mitochondrial capacity but may provoke anaerobic metabolism and acidosis, which can inhibit oxidative phosphorylation while also affecting the results (Robergs et al. 2004). This was probably reflected by prolonged time of $\mathrm{PCr}$ recovery $\tau_{\mathrm{PCr}}$ in subjects with a lower $\mathrm{pH}$ after the exercise (significant negative correlation between these two parameters was observed too). Moreover, acidosis may be another marker related to the DM1 disease and probably depends on sex. We found a significant difference between the $\mathrm{pH}$ values of male and female controls. It is in agreement with the findings described for quadriceps muscles (Schunk et al. 1999). Crowther et al. (2003) described decreased pH values in DM1 males; on the other hand, Item (Item et al.
2011) found no change in the DM1 females. Our findings are similar but without statistical significance.

Although one would expect a substantial impairment of the energy metabolism in relation to diabetes, we did not find any significant differences in metabolite ratios measured at rest between controls and diabetic patients without nephropathy (DM1m, DM1f, DM1). The DM1N group (all patients with nephropathy) had higher $\mathrm{Pi} / \mathrm{P}_{\text {tot }}$ and $\mathrm{PDE} / \mathrm{P}_{\text {tot }}$ while having lower $\beta-\mathrm{ATP} / \mathrm{P}_{\text {tot }}$ in comparison to healthy controls. In addition, DM1N group was distinguished from DM1 group in $\beta-\mathrm{ATP} / \mathrm{P}_{\text {tot }}$. However, when we differentiated patients according to sex, the only $\beta-\mathrm{ATP} / \mathrm{P}_{\text {tot }}$ was significantly lower in only males (Cm vs. DM1mN). In females' groups a similar trend in $\beta-\mathrm{ATP} / \mathrm{P}_{\text {tot }}$ was visible. Thus we can assume that the $\beta-\mathrm{ATP} / \mathrm{P}_{\text {tot }}$ ratio can be the best marker to separate patients with and without nephropathy.

Decreased ATP and increased Pi can be generally associated with kidney failure and uremia (Nishida et al. 1991, Taborsky et al. 1993). Similar metabolite changes were also described in mitochondrial disorders (Mattei et al. 2004) and indicate a reducing phosphorylation potential. It is in agreement with 
negative correlation between age and $\beta-\mathrm{ATP} / \mathrm{P}_{\text {tot }}$. Positive correlation between age and $\mathrm{PDE} / \mathrm{P}_{\text {tot }}$ can be considered consistent with an increasing BMI (Valkovic et al. 2016). In addition, the $\mathrm{pH}$ decrease after the exercise and an increase of $\mathrm{Pi} / \mathrm{P}_{\text {tot }}$ negatively influence $\tau_{\mathrm{PCr}}$.

Similar gender changes as at rest were observed in $\mathrm{pH}$ after the exercise between male and female controls. This difference was not observed in respect of the patients. Pooled data of the males and females without severe nephropathy (DM1) as well as the DM1m group only had a decreased $\mathrm{pH}$ after the exercise compared with the control group, which is probably related to the increased demand for $\mathrm{PCr}$ supply reflected also by a higher (but not statistically significant) drop of the PCr signal.

We should mention that an increased variation of obtained experimental data can also be explained by the variability of a patient's physical condition. Although all subjects filled in a questionnaire concerning their physical conditions, there was difficult to find out an objective parameter, which could help with the explanation of the data variability. Thus, only qualitative trends have to be discussed. It is the case of e.g. longer recovery time $\tau_{\mathrm{PCr}}$ in all DM1 groups compared to controls, which reflects a decreased mitochondrial capacity. From this qualitative point of view, our findings of $\mathrm{V}_{\mathrm{iPCr}}$ and $\mathrm{Q}_{\max }$ in the DM1 females are not consistent with the finding outlined in Item (Item et al. 2011), neither did we find any significant correlation of glycosylated hemoglobin reported in that paper.

Lower $\mathrm{V}_{\mathrm{iPCr}}$ and mitochondrial capacity $\mathrm{Q}_{\max }$ in the case of the DM1 male patients compared to DM1 females without kidney failure suggests that male metabolism is influenced by DM1 more than female metabolism. However, the fact that we did not observe a similar difference in patients with severe nephropathy remains unexplained; we may speculate that severe metabolic impairment smoothed moderate gender differences.

It is known that females have a lower efficiency in the effective use of ATP for muscle contraction (Mattei et al. 1999). We hypothesize that the lower efficiency is related to a different proportion of muscle fibers between males and females which could also cause a different (smaller) effect of DM1 on the muscle metabolism in females.

Gender differences may also reflect DM1-related changes in levels of several important hormones and factors affecting skeletal muscle atrophy, growth, and regeneration (Krause et al. 2011) and hypothetically may differ in males and females.

\section{Conclusions}

We have proven that nephropathy further negatively affects the energy metabolism in diabetic patients. It is reflected by reduced relative $\beta$-ATP and increased $\mathrm{Pi}$ and PDE signals to $\mathrm{P}_{\text {tot }}$ at rest and prolongation of the $\mathrm{PCr}$ recovery time after the exercise. Gender specific changes can be seen in healthy subjects in $\mathrm{pH}$ values both at rest and after the exercise. We have not confirmed any significant gender differences in the DM1 patients by ${ }^{31} \mathrm{P}$ MR spectroscopy in our groups of patients.

\section{Conflict of Interest}

There is no conflict of interest.

\section{Acknowledgements}

The study was supported by the project Grant Agency of Charles University (project No. 315) and MHCZ-DRO 00023001IKEM.

\section{References}

ANTONETTI DA, REYNET C, KAHN CR: Increased expression of mitochondrial-encoded genes in skeletal muscle of humans with diabetes mellitus. J Clin Invest 95: 1383-1388, 1995.

ARGOV Z, LÖFBERG M, ARNOLD DL: Insights into muscle diseases gained by phosphorus magnetic resonance spectroscopy. Muscle Nerve 23: 1316-1334, 2000.

BERGMAN BC, HOWARD D, SCHAUER IE, MAAHS DM, SNELL-BERGEON JK, ECKEL RH, PERREAULT L, REWERS M: Features of hepatic and skeletal muscle insulin resistance unique to type 1 diabetes. $J$ Clin Endocrinol Metab 97: 1663-1672, 2012.

BOSKA M: ATP production rates as a function of force level in the human gastrocnemius/soleus using 31P MRS. Magn Reson Med 32: 1-10, 1994.

BROWNLEE M: Biochemistry and molecular cell biology of diabetic complications. Nature 414: 813-820, 2001. 
CREE-GREEN M, NEWCOMER BR, BROWN MS, BAUMGARTNER AD, BERGMAN B, DREW B, REGENSTEINER JG, PYLE L, REUSCH JE, NADEAU KJ: Delayed skeletal muscle mitochondrial ADP recovery in youth with type 1 diabetes relates to muscle insulin resistance. Diabetes 64: 383-392, 2015.

CROWTHER GJ, MILSTEIN JM, JUBRIAS SA, KUSHMERICK MJ, GRONKA RK, CONLEY KE: Altered energetic properties in skeletal muscle of men with well-controlled insulin-dependent (type 1) diabetes. $\mathrm{Am}$ $J$ Physiol Endocrinol Metab 284: E655-E662, 2003.

DEVRIES DA, MARSH GD, RODGER NW, THOMPSON RT: Metabolic response of forearm muscle to graded exercise in type II diabetes mellitus: effect of endurance training. Can J Appl Physiol 21: 120-133, 1996.

FAHAL IH: Uraemic sarcopenia: aetiology and implications. Nephrol Dial Transplant 29: 1655-1665, 2014.

ITEM F, HEINZER-SCHWEIZER S, WYSS M, FONTANA P, LEHMANN R, HENNING A, WEBER M, BOESIGER P, BOUTELLIER U, TOIGO M: Mitochondrial capacity is affected by glycemic status in young untrained women with type 1 diabetes but is not impaired relative to healthy untrained women. Am J Physiol Regul Integr Comp Physiol 301: R60-R66, 2011.

KARAKELIDES H, ASMANN YW, BIGELOW ML, SHORT KR, DHATARIYA K, COENEN-SCHIMKE J, KAHL J, MUKHOPADHYAY D, NAIR KS: Effect of insulin deprivation on muscle mitochondrial ATP production and gene transcript levels in type 1 diabetic subjects. Diabetes 56: 2683-2689, 2007.

KEMP GJ: Interactions of mitochondrial ATP synthesis and the creatine kinase equilibrium in skeletal muscle. $J$ Theor Biol 170: 239-246, 1994.

KEMP GJ, AHMAD RE, NICOLAY K, PROMPERS JJ: Quantification of skeletal muscle mitochondrial function by 31P magnetic resonance spectroscopy techniques: a quantitative review. Acta Physiol (Oxf) 213: 107-144, 2015.

KEMP GJ, MEYERSPEER M, MOSER E: Absolute quantification of phosphorus metabolite concentrations in human muscle in vivo by 31P MRS: a quantitative review. NMR Biomed 20: 555-565, 2007.

KEMP GJ, RADDA GK: Quantitative interpretation of bioenergetic data from 31P and $1 \mathrm{H}$ magnetic resonance spectroscopic studies of skeletal muscle: an analytical review. Magn Reson Q 10: 43-63, 1994.

KEMP GJ, ROUSSEL M, BENDAHAN D, LE FUR Y, COZZONE PJ: Interrelations of ATP synthesis and proton handling in ischaemically exercising human forearm muscle studied by $31 \mathrm{P}$ magnetic resonance spectroscopy. J Physiol 535: 901-928, 2001.

KEMP GJ, TAYLOR DJ, RADDA GK: Control of phosphocreatine resynthesis during recovery from exercise in human skeletal muscle. NMR Biomed 6: 66-72, 1993.

KEMP GJ, THOMPSON CH, TAYLOR DJ, RADDA GK: ATP production and mechanical work in exercising skeletal muscle: a theoretical analysis applied to 31P magnetic resonance spectroscopic studies of dialyzed uremic patients. Magn Reson Med 33: 601-609, 1995.

KRAUSE MP, RIDDELL MC, HAWKE TJ: Effects of type 1 diabetes mellitus on skeletal muscle: clinical observations and physiological mechanisms. Pediatric Diabetes 12: 345-664, 2011.

LANZA IR, BHAGRA S, NAIR KS, PORT JD: Measurement of human skeletal muscle oxidative capacity by 31P-MR spectroscopy: a cross-validation with in vitro measurements. J Magn Reson Imaging 34: 1143-1150, 2011.

MATTEI JP, BENDAHAN D, COZZONE P: P-31 magnetic resonance spectroscopy. A tool for diagnostic purposes and pathophysiological insights in muscle diseases. Reumatismo 56: 9-14, 2004.

MATTEI JP, BENDAHAN D, ROUSSEL M, LEFUR Y, COZZONE PJ: Gender modulates the energy cost of muscle contraction in untrained healthy subjects. A 31P magnetic resonance spectroscopy analysis. FEBS Lett 450: 173-177, 1999.

MOON RB, RICHARDS JH: Determination of intracellular $\mathrm{pH}$ by 31P magnetic resonance. $J$ Biol Chem 248: 7276-7578, 1973.

NISHIDA A, KUBO K, NIHEI H: Impaired muscle energy metabolism in uremia as monitored by 31P-NMR. Nihon Jinzo Gakkai Shi 33: 65-73, 1991.

PERSEGHIN G, LATTUADA G, DANNA M, SERENI LP, MAFFI P, DE COBELLI F, BATTEZZATI A, SECCHI A, DEL MASCHIO A, LUZI L: Insulin resistance, intramyocellular lipid content, and plasma adiponectin in patients with type 1 diabetes. Am J Physiol Endocrinol Metab 285: E1174-E1181, 2003. 
PETERSEN KF, DUFOUR S, BEFROY D, GARCIA R, SHULMAN GI: Impaired mitochondrial activity in the insulin-resistant offspring of patients with type 2 diabetes. N Engl J Med 350: 664-671, 2004.

RABOL R, HOJBERG PM, ALMDAL T, BOUSHEL R, HAUGAARD SB, MADSBAD S, DELA F: Effect of hyperglycemia on mitochondrial respiration in type 2 diabetes. J Clin Endocrinol Metab 94: 1372-1378, 2009.

ROBERGS RA, GHIASVAND F, PARKER D: Biochemistry of exercise-induced metabolic acidosis. Am J Physiol Regul Integr Comp Physiol 287: R502-R516, 2004.

ROSSETTI L: Glucose toxicity: the implications of hyperglycemia in the pathophysiology of diabetes-mellitus. Clin Invest Med 18: 255-260, 1995.

SCHUNK K, PITTON M, DÜBER C, KERSJES W, SCHADMAND-FISCHER S, THELEN M: Dynamic phosphorus31 magnetic resonance spectroscopy of the quadriceps muscle: effects of age and sex on spectroscopic results. Invest Radiol 34: 116-125, 1999.

SEDIVY P, KIPFELSBERGER MC, DEZORTOVA M, KRSSAK M, DROBNY M, CHMELIK M, RYDLO J, TRATTNIG S, HAJEK M, VALKOVIC L: Dynamic 31P MR spectroscopy of plantar flexion: influence of ergometer design, magnetic field strength (3 and 7 T), and RF-coil design. Med Phys 42: 1678-1689, 2015.

SZENDROEDI J, RODEN M: Mitochondrial fitness and insulin sensitivity in humans. Diabetologia 51: 2155-2167, 2008.

TABORSKY P, SOTORNIK I, KASLIKOVA J, SCHUCK O, HAJEK M, HORSKA A: 31P magnetic resonance spectroscopy investigation of skeletal muscle metabolism in uraemic patients. Nephron 65: 222-226, 1993.

TAYLOR DJ, STYLES P, MATTHEWS PM, ARNOLD DA, GADIAN DG, BORE P, RADDA GK: Energetics of human muscle: exercise-induced ATP depletion. Magn Reson Med 3: 44-54, 1986.

VALKOVIČ L, CHMELÍK M, KRŠŠÁK M: In-vivo 31P-MRS of skeletal muscle and liver: A way for non-invasive assessment of their metabolism. Anal Biochem 529: 193-215, 2017.

VALKOVIC L, CHMELIK M, UKROPCOVA B, HECKMANN T, BOGNER W, FROLLO I, TSCHAN H, KREBS M, BACHL N, UKROPEC J, TRATTNIG S, KRSSAK M: Skeletal muscle alkaline Pi pool is decreased in overweight-to-obese sedentary subjects and relates to mitochondrial capacity and phosphodiester content. Sci Rep 6: 20087, 2016.

VANHAMME L, VAN DEN BOOGAART A, VAN HUFFEL S: Improved method for accurate and efficient quantification of MRS data with use of prior knowledge. J Magn Reson 129: 35-43, 1997.

WILCOX G: Insulin and insulin resistance: Clin Biochem Rev 26: 19-39, 2005.

YKI-JARVINEN H, SAHLIN K, REN JM, KOIVISTO VA: Localization of rate-limiting defect for glucose disposal in skeletal muscle of insulin-resistant type I diabetic patients. Diabetes 39: 157-167, 1990. 